\title{
Analysis of Dynamic Characteristics of Pressure-Regulating and Pressure-Limiting Combined Relief Valve
}

\author{
Rui Shi $\mathbb{D}^{1},{ }^{1}$ Chuanli Wang $\mathbb{D}^{1,2}$ Tao He $\mathbb{D}^{1,2}$ and Tian Xie $\mathbb{D}^{1}$ \\ ${ }^{1}$ School of Mechanical Engineering, Anhui University of Science and Technology, Huainan 232001, Anhui, China \\ ${ }^{2}$ Anhui Key Laboratory of Mine Intelligent Equipment and Technology, Huainan 232001, Anhui, China \\ Correspondence should be addressed to Chuanli Wang; chlwang@aust.edu.cn
}

Received 23 July 2020; Revised 14 March 2021; Accepted 19 March 2021; Published 29 March 2021

Academic Editor: Alessandro Mauro

Copyright (C) 2021 Rui Shi et al. This is an open access article distributed under the Creative Commons Attribution License, which permits unrestricted use, distribution, and reproduction in any medium, provided the original work is properly cited.

\begin{abstract}
Aiming at the problem of the lack of a cooperation mechanism of combined relief valves, this paper proposes a new pressure-regulating and pressure-limiting combined relief valve. Combined with the ordinary relief valve dynamic characteristic analysis method, the dynamic model of the combined relief valve under normal working conditions was established, and its dynamic characteristics were simulated using Simulink. The results showed that the multi-pressure stabilization design of the combined relief valve improves its usability and stability. Under the same structural parameters, the overshoot of the combined relief valve was $5.7 \%$, and the response time was $12 \mathrm{~ms}$, which is better than the ordinary relief valve. Besides, it effectively improves the instability problems, such as the vibration and the large pressure fluctuation of the ordinary relief valve under high pressure and large flow conditions. When the sum of the effective force area on the upper side of the flange of the pressureregulating valve core and the area of the tail vertebra is equal to the effective force area of the lower side of the flange of the pressure-regulating valve core, the dynamic performance of the relief valve is optimal. For example, if the effective force area under the flange is $1.8 \mathrm{~cm}^{2}$, then the inlet pressure overshoot is $2.8 \%$, and the response time is $10 \mathrm{~ms}$. An appropriate volume of the sensitive cavity, the quality of the valve core, and the fluid resistance of the pressure relief valve are factors that can effectively improve the dynamic performance of the pressure-regulating and pressure-limiting combined relief valve.
\end{abstract}

\section{Introduction}

Relief valves are key components of pressure regulation mechanisms in hydraulic systems, and their performance directly determines the pressure stability and the safety of hydraulic systems $[1,2]$. Many pieces of research work on the dynamic characteristics of relief valves have achieved valuable research results. For example, literature $[3,4]$ developed a pilot hydraulic relief valve and studied its stability with different orifice diameters and pilot valve spring stiffness values while also considering the influence of the volume of the cavity between the orifice and the pilot valve. Literature [5-7] put forward a design method of a permanent magnet direct-acting relief valve by replacing the traditional direct-acting spring with a permanent magnet spring. Studies and experimental investigations indicate that the relief valve has better opening and closing characteristics and a smaller volume. Because of the high stiffness of the magnetic spring, the valve port opening currently creates a large pressure fluctuation, which reduced the opening stability and pressure stabilization accuracy of the relief valve. Besides, the permanent magnet was made from a brittle material, which was expensive. Literature [8] established a dynamic characteristic model of the cone relief valve and analyzed the influence of its design parameters on the dynamic characteristics of the valve system. Literature $[9,10]$ analyzed the influences of the damping, orifice and cavity volumes, and other factors on the relief valve through modeling, simulations, and experiments, and they proposed that proper damping can effectively improve the dynamic performance of relief valves. Literature [11] proposed a direct-acting hydraulic pressure relief valve structure with a damping piston; by adding a countersink and a piston with a damping hole in front of the direct-acting relief valve, the 
polarisation of the cone valve was reduced, which improved the valve's working stability. Literature [12] designed a system with a double relief valve and a series connection of relief valves and accumulators. A simulation model was established with Simulink, and the simulation analysis showed that both systems could reduce the valve core fluctuation when the relief valve was under the pressure range, which enhanced the system stability. Literature [13] studied the stability of the plug-in relief valve and found that the impedance of the center damping hole of the spool valve has an important effect on the stability of the valve core. Literature [14], by introducing a damping tail with holes to the main poppet, analyzed the influence of the damping tail parameters on the flow force and achieved the best stability of the main poppet valve through the optimal parameter combination obtained by calculation. Literature [15] used the computational fluid dynamics approach to study the flow process inside the pressure-regulating valve, and the influence of flow force on the stability of the pressure-regulating valve was analyzed. Also, literature $[16,17]$ started from the distribution state and the compound mode of different damping values and explored the stability mechanisms and capacity evaluation systems of pressure valves based on compound damping control. Literature [18-20] analyzed the collision mode of the cone and the valve seat, established a stable region diagram of the cone valve vibration, and revealed the mutual transfer law of axial energy and radial energy. Considering some factors, such as the distributed parameter characteristics of pipelines, the nonlinear collision between the cone and the valve seat, the viscous force of the fluid, and the interaction between the cavitation and the cone, a criterion for determining the criterium for bidirectional vibration stability of the cone valve was established.

Although the above scholars have done a lot of research on improving the dynamic performance of relief valves, they have mainly focused on optimizing the structural parameters and mechanism analyses. Regarding the dynamic performance stability analysis of the integrated design of the combined relief valve, relevant research is relatively rare. Also, the matching relationships between the key parameters of relief valves are still not clear. With the development needs of high-speed heavy-duty hydraulic systems, it is necessary to achieve multifunctionality in a limited space, stably meet the pressure of large flow rates promptly, and often adopt a combined design method of hydraulic components $[21,22]$. Thus, this paper proposes a pressure-regulating and pressure-limiting combined relief valve through structural innovation. The special valve core structure provides a large preload for the relief valve. Besides, the pressure in the sensitive chamber of the pressurelimiting valve is used to reduce the inlet pressure fluctuation. When the inlet pressure increases to the specified pressure of the pressure-limiting valve, the pressure-limiting and pressure-regulating valves are synchronously opened, which instantly realizes the rapid pressure relief. This paper combines the above scholars' research methods on the dynamic characteristics of ordinary relief valves and establishes a mathematical model of the combined relief valve. Using Simulink software, their dynamic characteristics under normal working conditions were simulated, analyzed, and compared to ordinary pressure relief valve, and for the cooperative working mechanism of the combined pressure relief valve, a matching relationship between the areas of all ends of the pressure-regulating valve core was established. Comparing the influence of sensitive cavity volume, pressure-limiting valve liquid resistance, and valve core mass on the dynamic performance guides the design and manufacture of the combined relief valve. Besides, it has high application value in construction machinery, mining machinery, and grinding machinery with a bad working environment.

\section{The Working Principle of the Pressure- Regulating and Pressure-Limiting Combined Relief Valve}

Figure 1 shows a schematic diagram of the structure of the pressure-regulating and pressure-limiting combined relief valve, which is composed of a pressure-regulating valve, a pilot valve, and a pressure-limiting valve. The tail part of the pressure-regulating valve core is provided with a concaveconvex structure and a tail vertebra and connected with the sensitive cavity of the pressure-limiting valve; step seal is used between the tail and seat to avoid leakage. The pilot valve seat adopts a separate cone valve seat structure, which is easy to replace and install and is suitable for high-pressure and large-flow fluid transmission systems. The tail cone of the pressure-regulating valve core and the concave-convex structure cooperate to make the two valves cooperate, thus realizing two core functions, namely, pressure regulation and pressure limitation. Figure 2 shows a schematic diagram of the working principle of the pressure-regulating and pressure-limiting combined relief valve. After hydraulic oil enters from the oil inlet, it, respectively, leads to two oil paths. Oil path 1 acts on the lower end surface of the pressure-regulating valve core to provide inlet pressure $p_{1}$ and flows into the front cavity of the pilot valve through hydraulic resistances $R_{1}$ and $R_{2}$. When the system pressure increases to make the valve core of the pilot valve open, the hydraulic oil flows back to the tank through the spring cavity of the pilot valve. Due to the effect of hydraulic resistance, the inlet pressure of the pressure-regulating valve is greater than that of the sensitive cavity of the pressure-regulating valve; under the action of pressure difference, the spring force is overcome to move upward, and the valve port is opened to realize the overflow effect. As for oil path 2, it enters the sensitive cavity of the pressure-limiting valve through the fluid resistance $R_{3}$, acts on the tail spine of the pressure-regulating valve core, and generates a hydraulic pressure $p_{3}$ with the opposite control pressure, which provides a large preload for the relief valve and ensures a small stiffness of the pilot spring. The combined relief valve utilizes the pressure in the valve cavity of the pressure-limiting valve to cooperate with the pressure of the valve cavity of the pressure-regulating valve and the spring force to stabilize the valve core of the pressure-regulating valve, thus improving the opening stability of the overflow 


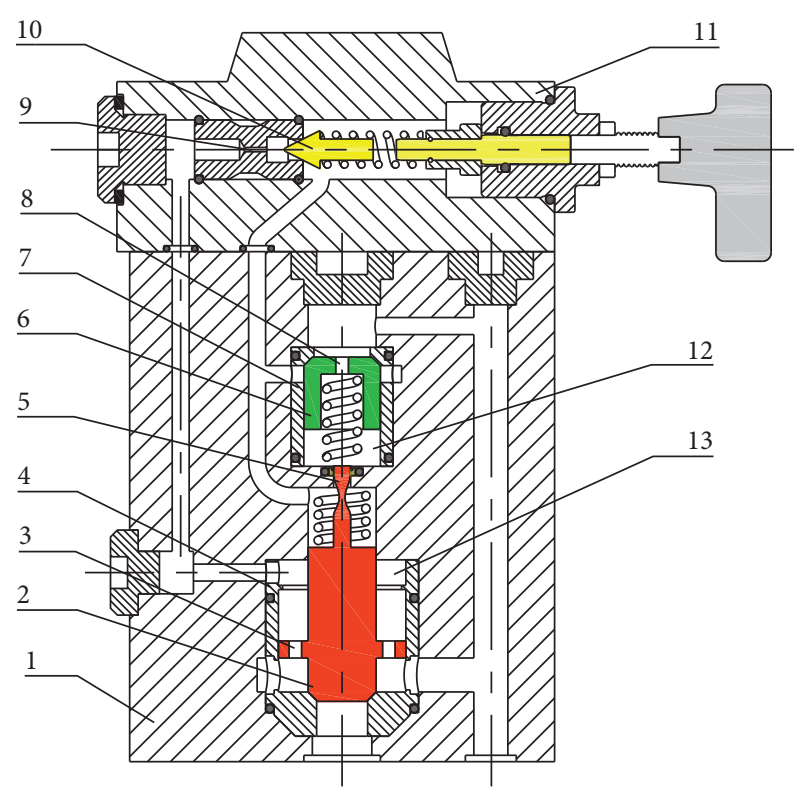

FIgURE 1: Structure diagram of the pressure-regulating and pressure-limiting combined relief valve. 1, pressure-regulating valve body; 2 , pressure-regulating valve core; 3 , pressure-regulating valve liquid resistance $R_{1} ; 4$, pressure-regulating valve sleeve; 5 , pressure-regulating valve tail vertebra; 6 , pressure-limiting valve core; 7 , pressure-limiting valve sleeve; 8 , pressure-limiting valve liquid resistance $R_{3} ; 9$, pilot valve liquid resistance $R_{2} ; 10$, pilot valve core; 11, pilot valve body; 12, pressure-limiting valve sensitive cavity; 13 , pressure-regulating valve sensitive cavity.

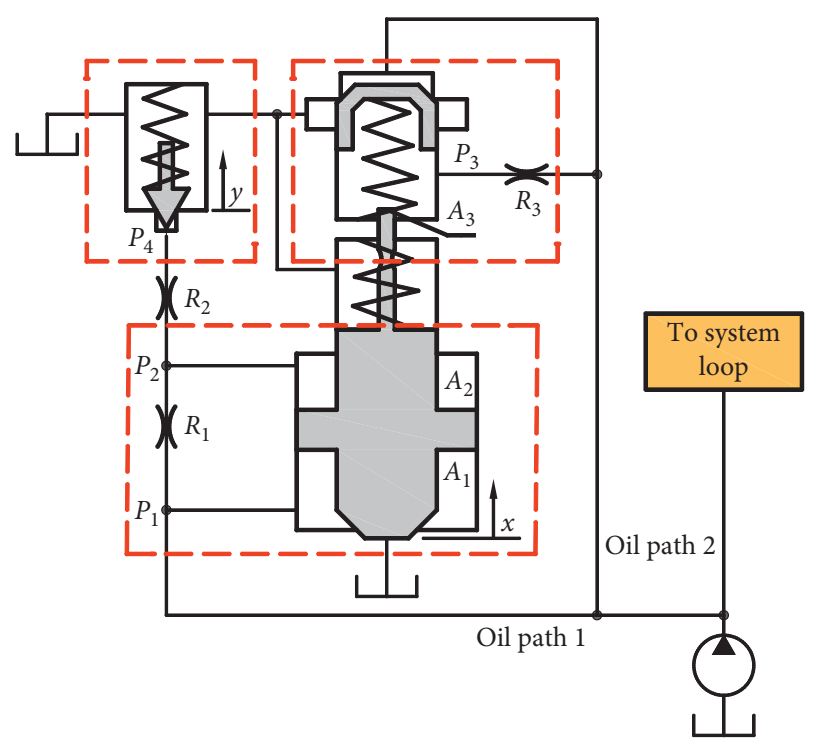

FIGURE 2: Working principle diagram of the combined relief valve.

valve and the pressure regulation resolution. During the opening of the valve core, the hydraulic pressure $p_{3}$ on the end surface of the caudal vertebra has a similar fluctuation law to that of the inlet pressure $p_{1}$, and it can partially offset the fluctuation of the inlet pressure. Throughout the normal operation, the pressure relief valve remains closed and the fluid pressure $p_{3}$ of the cavity of the pressure relief valve remains static pressure, providing stability and increasing the stability of the combined relief valve during operation, and is beneficial for reducing the working noise caused by vibration. When the inlet pressure increases to the specified pressure of the pressure-limiting valve, the concave-convex structure of the valve core makes the pressure-limiting valve sensitive cavity communicate with the pressure-regulating valve spring cavity, the pressure-limiting and pressureregulating valves are synchronously opened, and the double valves are relieved of the pressure, which is beneficial to the release of high pressure and large flow, thus ensuring the system safety. It can be seen from the above working principle that in the pressure-regulating and pressure-limiting combined relief valve designed in this paper, the spring of the pressure-regulating valve and the spring of the pressure-limiting valve are soft, and the spring of the pilot valve is harder, effectively avoiding the resonance phenomenon caused by the direct use of the pressurelimiting valve and the pressure-regulating valve due to the close control pressure. At the same time, because the pressure-regulating valve, the pressure-limiting valve, and the pilot valve coexist in one, the structure is compact.

\section{Model Establishment of the Pressure- Regulating and Pressure-Limiting Combined Relief Valve}

3.1. Mathematical Model of the Valve. To simplify the analysis and processing, the following assumptions were made when establishing the characteristic equation.

(i) The hydraulic oil quality has little effect on the dynamic characteristics of the valve, and its influence was ignored in the modeling process.

(ii) Considering that the frictional force, inertial force, and clamping force acting on the valve core of the pressure-regulating and pressure-limiting combined relief valve have small values, their influence was ignored in the modeling process.

(iii) The valve core and the valve body are precisely matched with no gap, so the internal and external leakages of the valve were not considered in the modeling process.

(iv) Because of the extremely small distance between the valve core and the sleeve, it was assumed that the valve core only moved in a single degree of freedom along its axis, so its rotational movement and the movement perpendicular to its axis were ignored.

Under the above assumptions, the mathematical model of the dynamic characteristics of the combined pressurelimiting and pressure-regulating relief valve can be expressed using the following equation.

3.1.1. Force Balance Equation of the Pressure-Regulating Valve Core. When working, the main force on the valve core consists of hydraulic pressure, mass inertial force, viscous frictional, spring force, steady-state hydrodynamic force, 
and transient hydrodynamic force. The valve core force balance equation is described by the following equation:

$$
\begin{aligned}
p_{1} A_{1}-p_{2} A_{2}-p_{3} A_{3}= & m_{1} \frac{\mathrm{d}^{2} x}{\mathrm{~d} t^{2}}+\left(B_{\mathrm{s} 1}+B_{\mathrm{x}}\right) \frac{\mathrm{d} x}{\mathrm{~d} t} \\
& +K_{\mathrm{x}}\left(x+x_{0}\right)+B_{\mathrm{w} 1} x,
\end{aligned}
$$

where

$$
\begin{aligned}
& B_{\mathrm{s} 1}=\rho L C_{\mathrm{d}} \pi D_{1}\left(1-\frac{x \sin 2 \varphi}{2 D_{1}}\right) \sin \varphi \sqrt{\frac{2 p_{1}}{\rho}}, \\
& B_{\mathrm{w} 1}=C_{\mathrm{d}} \pi D_{1}\left(1-\frac{x \sin 2 \varphi}{2 D_{1}}\right) \sin 2 \varphi p_{1},
\end{aligned}
$$

where $p_{1}$ is the inlet pressure of the pressure-regulating valve; $A_{1}$ is the effective force-bearing area under the flange of the pressure-regulating valve core; $p_{2}$ is the sensitive cavity pressure of the pressure-regulating valve; $A_{2}$ is the effective force-bearing area on the upper side of the pressureregulating valve core flange; $p_{3}$ is the sensitive cavity pressure of the pressure-limiting valve; $A_{3}$ is the effective forcebearing area of pressure-regulating valve tail vertebra; $m_{1}$ is the quality of the pressure-regulating valve core; $x$ is the valve opening of the pressure-regulating valve core; $B_{\mathrm{s} 1}$ is the pressure-regulating valve transient hydrodynamic damping; $B_{\mathrm{x}}$ is the viscous damping coefficient of the pressureregulating valve; $K_{\mathrm{x}}$ is the pressure-regulating valve return spring stiffness; $x_{0}$ is the precompression of the pressureregulating valve spring; $B_{\mathrm{w} 1}$ is the pressure-regulating valve core steady-state hydrodynamic stiffness; $C_{\mathrm{d}}$ is the flow coefficient of the relief valve; $D_{1}$ is the diameter of the pressure-regulating valve; $\varphi$ is the pressure-regulating valve core half cone angle; $\rho$ is the density of the fluid; and $L$ is the pressure-regulating valve damping length.

\subsubsection{Pressure and Flow Equation of the Pressure-Regulating} Valve Core Port.

$$
q_{\mathrm{x}}=C_{\mathrm{d}} \pi D_{1}\left(1-\frac{x \sin 2 \varphi}{2 d_{1}}\right) \sin \varphi \sqrt{\frac{2 p_{1}}{\rho}},
$$

where $q_{\mathrm{x}}$ is the overflow of the pressure-regulating valve.

\subsubsection{Force Balance Equation of the Pilot Valve Core.} The pilot valve core follows the traditional direct-acting poppet valve structure. Since the flow through the pilot valve is relatively small, the steady-state hydrodynamic force is along the direction in which the pilot valve core tends to close and change linearly. Therefore, the transient hydrodynamic force of the pilot valve can be ignored [23]. The force acting on the pilot valve core mainly includes the hydraulic pressure, mass inertial force, viscous frictional, spring force, and steady-state hydrodynamic force in the front cavity of the pilot valve. The force balance equation of the valve core is shown in the following equation:

$$
p_{4} A_{4}=m_{2} \frac{\mathrm{d}^{2} y}{\mathrm{~d} t^{2}}+B_{\mathrm{y}} \frac{\mathrm{d} y}{\mathrm{~d} t}+K_{\mathrm{y}}\left(y+y_{0}\right)+B_{\mathrm{w} 2} y
$$

where

$$
B_{\mathrm{W} 2}=C_{\mathrm{d}} \pi D_{2}\left(1-\frac{y \sin 2 \alpha}{2 D_{2}}\right) \sin 2 \alpha p_{1} \text {, }
$$

where $p_{4}$ is the hydraulic pressure of the pilot valve core; $m_{2}$ is the valve core quality of the pilot valve; $y$ is the pilot valve core displacement; $B_{\mathrm{y}}$ is the viscous damping coefficient of the pilot valve; $K_{\mathrm{y}}$ is the spring stiffness of the pilot valve; $y_{0}$ is the precompression of the pilot valve spring; $B_{\mathrm{w} 2}$ is the pilot valve core steady-state hydrodynamic force; and $\alpha$ is the pilot valve core half cone angle.

\subsubsection{Pilot Valve Pressure and Flow Equation.}

$$
q_{\mathrm{y}}=C_{\mathrm{d}} \pi\left[\left(\frac{D_{2}}{2 \cos \alpha}\right)^{2}-\left(D_{2}-y \sin \alpha \cos \alpha\right)^{2}\right] \sqrt{\frac{2 p_{4}}{\rho}},
$$

where $D_{2}$ is the diameter of the pilot valve.

\subsubsection{Flow Equation Flowing through a Fixed Liquid} Resistance. It can be seen from the structure of the relief valve that the inlet flow enters the sensitive chamber of the pressure- regulating valve through the liquid resistance R1 which is a thin-walled hole, and its pressure-flow equation is

$$
q_{1}=C_{\mathrm{n}} \frac{\pi d_{\mathrm{n} 1}^{2}}{4} \sqrt{\frac{2\left(p_{1}-p_{2}\right)}{\rho}}
$$

where $q_{1}$ is the flow through the liquid resistance $R_{1} ; C_{\mathrm{n}}$ is the liquid resistance flow coefficient; and $d_{\mathrm{n} 1}$ is the diameter of the liquid resistance $R_{1}$.

For the liquid resistance $R_{3}$, the structure is also designed as a thin wall hole, and its pressure-flow equation is

$$
q_{3}=C_{\mathrm{n}} \frac{\pi d_{\mathrm{n} 3}^{2}}{4} \sqrt{\frac{2\left(p_{3}-p_{1}\right)}{\rho}},
$$

where $q_{3}$ is the flow through the liquid resistance $R_{3}$ and $d_{\mathrm{n} 3}$ is the diameter of the liquid resistance $R_{3}$.

For the liquid resistance $R_{2}$, the structure is an elongated hole-type liquid resistance, which is different from the thin wall hole liquid resistance whose pressure loss is mainly local. However, the elongated hole-type liquid resistance is mainly the pressure loss along the way, which is mainly caused by the viscous friction of hydraulic oil. Generally speaking, the flow state of hydraulic oil in the hydraulic resistance of the elongated hole is laminar flow, and its pressure-flow equation is

$$
q_{2}=\frac{\pi d_{\mathrm{n} 2}^{4}}{128 \mu l}\left(p_{2}-p_{4}\right)
$$


where $q_{2}$ is the flow through the liquid resistance $R_{2} ; d_{\mathrm{n} 2}$ is the diameter of the liquid resistance $R_{2} ; \mu$ is the absolute viscosity of the fluid; and $l$ is the length of the liquid resistance $R_{2}$.

3.1.6. Flow Continuity Equation. According to the continuity of the liquid flow, without considering the radial leakage loss of the valve core, the flow continuity equation can be obtained as

$$
\begin{aligned}
Q & =q_{1}+q_{x}+\frac{V_{1}}{E} \frac{\mathrm{d} p_{1}}{\mathrm{~d} t}+A_{1} \frac{\mathrm{d} x}{\mathrm{~d} t}, \\
q_{1} & =q_{2}+\frac{V_{2}}{E} \frac{\mathrm{d} p_{2}}{\mathrm{~d} t}-A_{2} \frac{\mathrm{d} x}{\mathrm{~d} t}, \\
q_{2} & =q_{y}+\frac{V_{4}}{E} \frac{\mathrm{d} p_{4}}{\mathrm{~d} t}+A_{4} \frac{\mathrm{d} y}{\mathrm{~d} t}, \\
q_{3}+\frac{V_{3}}{E} \frac{\mathrm{d} p_{1}}{\mathrm{~d} t} & =A_{3} \frac{\mathrm{d} x}{\mathrm{~d} t},
\end{aligned}
$$

where $Q$ is the flow into the valve body; $V_{1}$ is the controlled volume under the flange of the pressure-regulating valve; $E$ is the elastic modulus of the fluid; $V_{2}$ is the controlled volume of the pressure-regulating valve sensitive cavity; $V_{3}$ is the controlled volume of the pressure-limiting valve sensitive cavity; and $V_{4}$ is the controlled volume of the pilot valve front chamber.

\subsection{Linearization of the Differential Equations and the Laplace}

Transform. When the pressure-regulating and pressurelimiting relief valve works in a stable state, the above equations include nonlinear equations. To determine the relationship between the pressure, valve core displacement, and time variables at a given flow step, the above equations need to perform linearization and Laplace transform. Set the steady-state operating point to $\left(X_{\mathrm{S}}, Y_{\mathrm{S}}, P_{1 \mathrm{~S}}, P_{2 \mathrm{~S}}, P_{3 \mathrm{~S}}, P_{4 \mathrm{~S}}\right)$. From equation (3), the linearization equation of the pressure-regulating valve flow is

$$
\frac{\mathrm{d} q_{\mathrm{x}}}{\mathrm{d} t} \approx k_{\mathrm{qx}} \frac{\mathrm{d} x}{\mathrm{~d} t}+k_{\mathrm{qy}} \frac{\mathrm{d} p_{1}}{\mathrm{~d} t},
$$

where

$$
\begin{aligned}
k_{\mathrm{qx}}= & \left.\frac{\partial q_{\mathrm{x}}}{\partial x}\right|_{x=x_{s}, P_{1}=P_{1 s}}=C_{\mathrm{d}} \pi D_{1} \sin \varphi \sqrt{\frac{2 P_{1 s}}{\rho}} \\
& -C_{\mathrm{d}} \pi D_{1} \sin 2 \varphi \frac{x_{s}}{d_{1}} \sqrt{\frac{2 P_{1 s}}{\rho}}, \\
k_{\mathrm{cx}}= & \left.\frac{\partial q_{\mathrm{x}}}{\partial P_{1}}\right|_{x=x_{s}, P_{1}=P_{1 s}}=C_{\mathrm{d}} \pi D_{1} x_{s} \sin \varphi \sqrt{\frac{1}{2 \rho P_{1 s}}} \\
& -C_{\mathrm{d}} \pi D_{1} \sin 2 \varphi \sin \varphi \frac{x_{s}^{2}}{2 d_{1}} \sqrt{\frac{1}{2 \rho P_{1 s}}},
\end{aligned}
$$

where $k_{\mathrm{qx}}$ is the pilot valve port flow gain and $k_{\mathrm{cx}}$ is the pilot valve port flow pressure coefficient.

From equation (7), the linearization equation of the damping hole $R_{1}$ of the pressure-regulating valve is

$$
\frac{\mathrm{d} q_{1}}{\mathrm{~d} t}=G_{\mathrm{rl}}\left(\frac{\mathrm{d} q_{1}}{\mathrm{~d} P_{1}}-\frac{\mathrm{d} q_{1}}{\mathrm{~d} P_{2}}\right),
$$

where

$$
G_{r 1}=C_{n} \frac{\pi d_{\mathrm{n} 1}^{2}}{4} \sqrt{\frac{1}{2 \rho\left(P_{1 s}-P_{2 s}\right)}} .
$$

By substituting equations (14) and (16) into equation (10) and performing the Laplace transform, then

$$
\begin{aligned}
Q(s)= & G_{r 1}\left[P_{1}(s)-P_{2}(s)\right]+\left(A_{1} s+K_{\mathrm{qx}}\right) X(s) \\
& +\left(\frac{V_{1}}{E} s+K_{\mathrm{cx}}\right) P_{1}(s) .
\end{aligned}
$$

Similarly, we can get

$$
\begin{gathered}
\left(\frac{V_{4}}{E} s+G_{r 3}\right) P_{3}(s)=G_{r 3} P_{1}(s)+A_{3} s X(s), \\
G_{r 1}\left[P_{1}(s)-P_{2}(s)\right]-G_{r 2}\left[P_{2}(s)-P_{4}(s)\right] \\
+A_{2} s X(s)=\frac{V_{2}}{E} s P_{2}(s) \\
X(s)=\frac{A_{1} P_{1}(s)-A_{2} P_{2}(s)-A_{3} P_{3}(s)}{m_{1} s^{2}+\left(B_{\mathrm{x}}+B_{\mathrm{s} 1}\right) s+K_{\mathrm{x}}+B_{\mathrm{w} 1}} \\
P_{4}(s)=\frac{G_{r 2} P_{2}(s)-\left(A_{4} s+K_{\mathrm{qy}}\right) Y(s)}{\left(V_{3} s / E\right)+G_{r 2}+K_{\mathrm{cy}}} \\
Y(s)=\frac{A_{4} P_{4}(s)}{m_{2} s^{2}+B_{y} s+K_{\mathrm{y}}+B_{\mathrm{w} 2}}
\end{gathered}
$$

3.3. Valve Simulation Model. According to equations (19)-(23), the block diagram model of the combined relief valve was established, as shown in Figure 3 . When the tail vertebra area $A_{3}$ was set to 0 , the pressure-limiting valve did not affect the operation of the pressure-regulating valve, which can be regarded as a block diagram model of an ordinary pilot relief valve. When both the pressureregulating valve and the pilot valve are open and working normally, in Figure 3(a), the input is the input flow $Q$ of the pressure-regulating and pressure-limiting relief valve and the output is the inlet pressure $p_{1}$ and the valve opening $x$. In Figure $3(b)$, the input of the pilot valve is the hydraulic pressure $p_{2}$ and the output is the hydraulic pressure $p_{4}$. In Figure $3(\mathrm{c})$, the input of the pressure-limiting valve is the inlet pressure $p_{1}$ and valve opening $x$ and the output is hydraulic pressure $p_{3}$.

In Figure 3: 


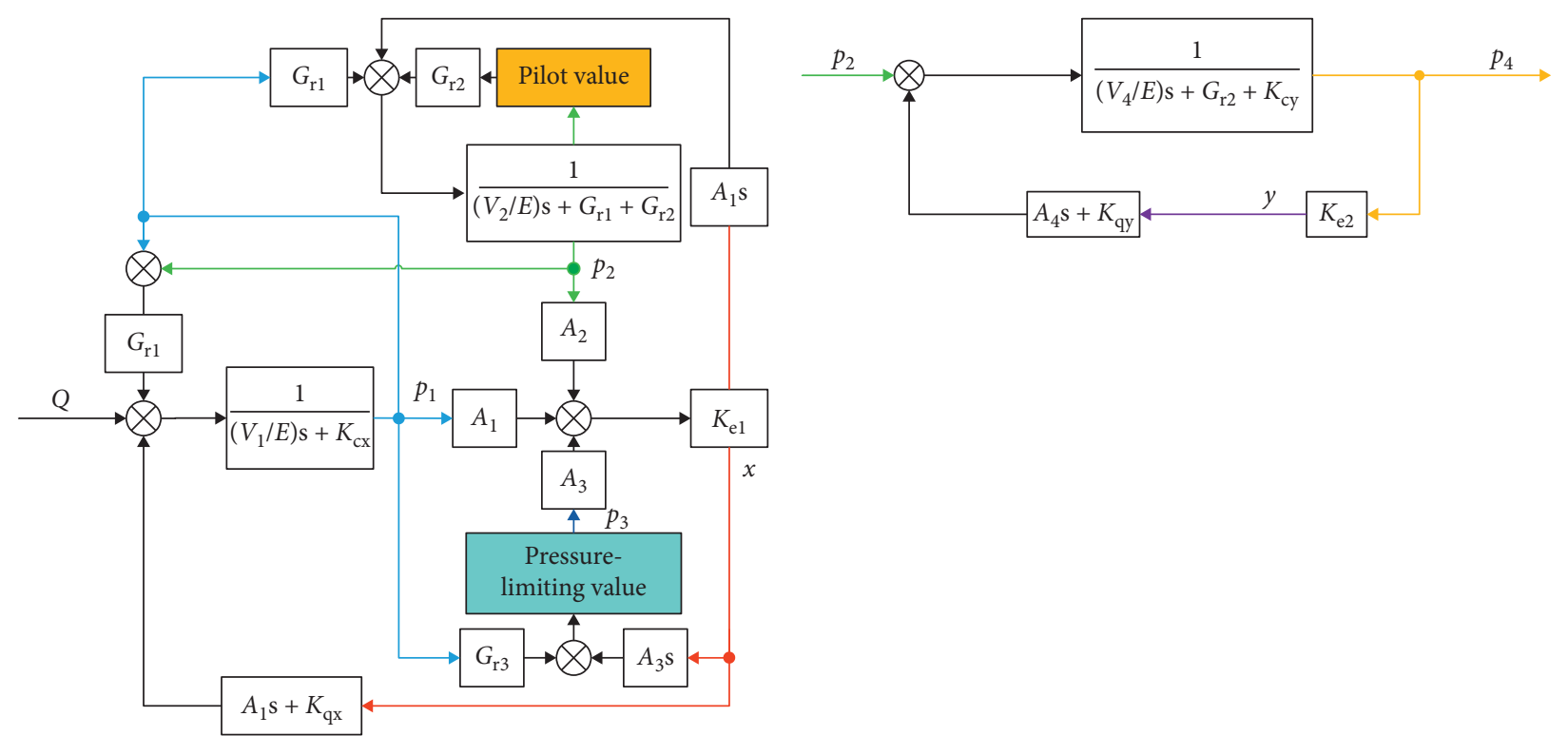

(a)

(b)

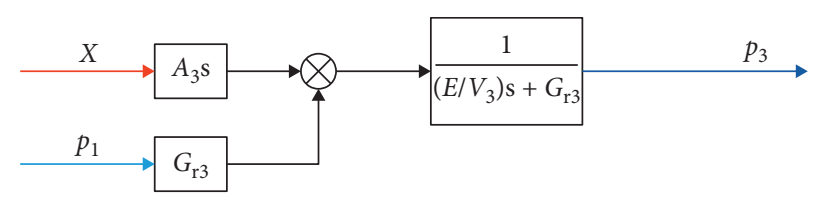

(c)

FIGURE 3: Simulation block diagram model of the pressure-regulating and pressure-limiting combined relief valve. (a) Block diagram of the pressure-regulating valve. (b) Block diagram of the pilot valve. (c) Block diagram of the pressure-limiting valve.

$$
\begin{aligned}
& K_{e 1}=\frac{1}{m_{1} s^{2}+\left(B_{\mathrm{x}}+B_{\mathrm{s} 1}\right) s+K_{\mathrm{x}}+B_{\mathrm{w} 1}}, \\
& K_{e 2}=\frac{A_{4}}{m_{2} s^{2}+B_{\mathrm{y}} s+K_{\mathrm{y}}+B_{\mathrm{w} 2}} .
\end{aligned}
$$

\section{Results and Analysis}

According to the block diagram of the pressure-regulating and pressure-limiting relief valve established in Figure 3, Simulink software was used to establish its model. The variable step-size Runge-Kutta algorithm was used for numerical simulation to investigate different factors. The impact on the dynamic performance of the relief valve was recorded.

\subsection{Dynamic Performance Comparison with Ordinary Pilot} Relief Valve. The relevant parameters of ordinary pilot relief valve are shown in Table 1.

From the working principle of the pressure-regulating and pressure-limiting combined relief valve, it can be concluded that the pressure stabilizing principle of the valve is similar to that of the ordinary pilot relief valve, where the main difference is the main valve core of the pressure-regulating valve. When the value of $A_{3}$ is 0 , the pressure-limiting valve does not affect the operation of the pressure-regulating valve. Using Simulink and the block diagram shown in Figure 3, the ordinary pilot relief valve
TABLE 1: Relevant parameters of ordinary pilot relief valve.

\begin{tabular}{lccc}
\hline Physical quantity & $\begin{array}{c}\text { Parameter } \\
\text { value }\end{array}$ & $\begin{array}{c}\text { Physical } \\
\text { quantity }\end{array}$ & $\begin{array}{c}\text { Parameter } \\
\text { value }\end{array}$ \\
\hline$m_{1}(\mathrm{~kg})$ & 0.1 & $m_{2}(\mathrm{~kg})$ & 0.01 \\
$A_{1}\left(\mathrm{~cm}^{2}\right)$ & 1.4 & $A_{2}\left(\mathrm{~cm}^{2}\right)$ & 1.4 \\
$K_{\mathrm{x}}(\mathrm{kN} / \mathrm{m})$ & 1000 & $K_{\mathrm{y}}(\mathrm{kN} / \mathrm{m})$ & 30000 \\
$D_{1}(\mathrm{~mm})$ & 8 & $D_{2}(\mathrm{~mm})$ & 4 \\
$\varphi(\mathrm{rad})$ & $\pi / 6$ & $\alpha(\mathrm{rad})$ & $\pi / 15$ \\
$V_{1}\left(\mathrm{~cm}^{3}\right)$ & 50 & $C_{\mathrm{d}}$ & 0.8 \\
$V_{2}\left(\mathrm{~cm}^{3}\right)$ & 5 & $C_{\mathrm{n}}$ & 0.61 \\
$V_{3}\left(\mathrm{~cm}^{3}\right)$ & 5 & $d_{\mathrm{n} 1}(\mathrm{~mm})$ & 1 \\
$\rho\left(\mathrm{kg} \cdot \mathrm{m}^{-3}\right)$ & 870 & $d_{\mathrm{n} 2}(\mathrm{~mm})$ & 1 \\
$\mu(\mathrm{Pa} \cdot \mathrm{s})$ & 0.051 & $E(\mathrm{MPa})$ & 1700 \\
\hline
\end{tabular}

simulation results could be obtained by solving the fourthorder Runge-Kutta algorithm. The pressure end of the pressure-regulating valve core was set to $A_{1}=1.4 \mathrm{~cm}^{2}$, $A_{2}=1.2 \mathrm{~cm}^{2}$, and $A_{3}=0.2 \mathrm{~cm}^{2}$. The other parameters are consistent with the ordinary pilot relief valve, and the simulation results of the combined relief valve can be obtained. The hydraulic resistance of the pressure-limiting pressure relief valve is a thin wall hole with a diameter of $d_{\mathrm{n} 3}=1.4 \mathrm{~mm}$, and the volume of the sensitive cavity of the pressure-limiting valve is $V_{3}=15 \mathrm{~mm}^{3}$.

The inlet pressure characteristic curves of the two relief valves are shown in Figure 4, and the inlet flow rate of the relief valve is $80 \mathrm{~L} / \mathrm{min}$. Under this set of parameters, the two relief valves have the same set pressure. For the relief valve, 


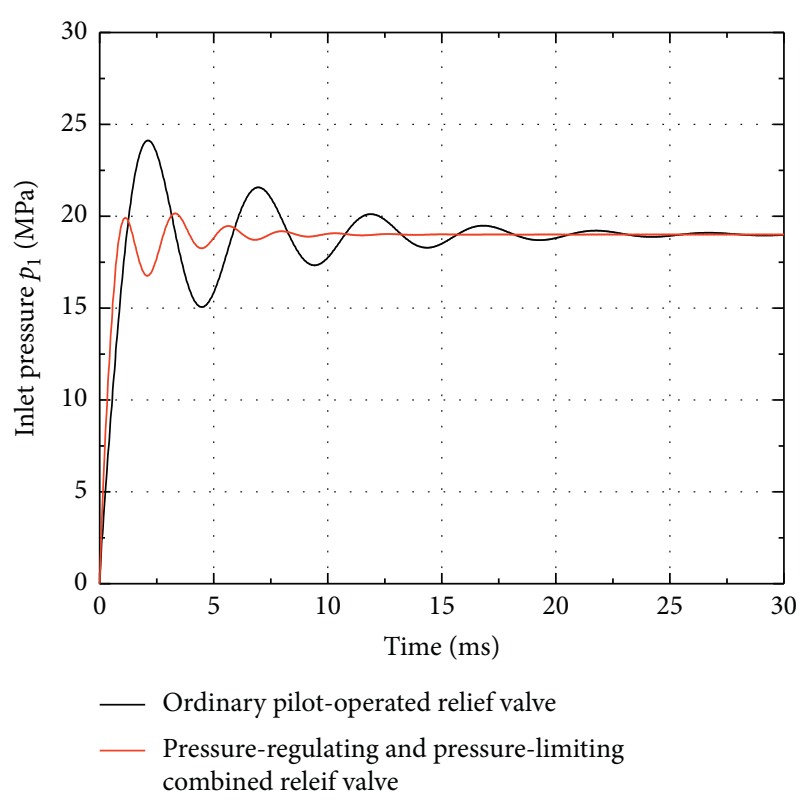

FIgURE 4: $p_{1}-t$ curve under two pressure relief valve flow steps.

under the control of the high-pressure oil, there is a certain amount of overshoot when the main valve opens, and the response time is longer. For the combined relief valve, due to the effect of the pressure-limiting valve chamber on the tail of the pressure-regulating valve core, the open-loop gain of the pressure-regulating valve core circuit is reduced, and the inlet pressure fluctuation is effectively suppressed. When the pressure-regulating valve core vibrates, a small amount of liquid will flow from the orifice of the pressure-limiting valve core, and a certain damping force will be generated, which is beneficial to the stability of the valve core. The overshoot, boost time, and transition time of the combined pressure relief valve are less than those of the former, which shows that the pressure-regulating and pressure-limiting combined relief valve can reduce pressure fluctuations and has a better dynamic performance. The inlet pressure of the combined relief valve is stable at $19 \mathrm{MPa}$, and the pressure overshoot is 1.7 $\mathrm{MPa}$, all of which meet the design requirements and have good accuracy regarding the pressure regulation resolution. Table 2 compares the dynamic performance parameters of the two relief valves at the same set pressure.

Figure 5 shows the displacement characteristic curves of the pilot valve cores of the two relief valves. Due to the high rigidity of the pilot spring, under high pressure, the pilot valve core causes large pressure fluctuations and valve core vibrations at the instant of opening. For the combined pressure-limiting and pressure-regulating relief valve, the hydraulic pressure acting on the tail vertebra of the pressure-regulating valve core provides the preloading force for the relief valve and partly replaces the spring stiffness of the pilot valve, which makes the spring force change a little to the better. The opening stability of the pilot valve core and the accuracy of the pressure regulation resolution is improved. The valve cores of the combined relief valve move less violently, and the stability of the pilot valve is improved, which is beneficial for improving the sealing between the valve core and the seat, thereby increasing their lifetime.
4.2. Effect of the Pressure-Regulating Valve Core Area. To achieve a better cooperative effect of pressure regulation and pressure limiting, it is necessary to analyze the area ratio of each end surface, that is, the appropriate relationship between the area of effective force area $A_{1}$ on the lower side of the flange of the pressure-regulating valve core, the effective force area $A_{2}$ at the upper side of the flange of the pressure-regulating valve core, and the force end face $A_{3}$ of the tail vertebra. Therefore, it is necessary to explore the influence of the relationship between $A_{2}+A_{3}$ and $A_{1}$ on the dynamic characteristics of the combined pressure-limiting pressure-relief valve and the range of pressure regulation. Take three sets of different parameter schemes: $A_{1} \geq A_{2}+A_{3}$, $A_{1} \leq A_{2}+A_{3}$, and $A_{1}=A_{2}+A_{3}$. Table 3 shows the test program under three different parameters of the end face area of the force, and Figure 6 represents a simulation result of the pressure port pressure $p_{1}$ of the pressure control valve with the parameters in Table 3 . The following conclusions can be drawn through analysis.

(1) There is a certain matching relationship between the areas $A_{1}, A_{2}$, and $A_{3}$ of the pressure-regulating valve core. When the values of $A_{2}+A_{3}$ and $A_{1}$ are the same, the control characteristics of the valve can be effectively improved. It can be seen from Figure 6(a) that when $A_{1}>A_{2}+A_{3}$, the greater the difference between $A_{2}+A_{3}$ and $A_{1}$, the more violent the valve inlet pressure vibration, and the response time is significantly improved. The inlet stabilizing pressure of program $\mathrm{h}$ is 1.32 times the inlet stabilizing pressure of program a, which is because the smaller the area of the stressed end of the caudal vertebrae is, the smaller the backpressure effect of the pressure-regulating valve core is and the easier the pressure-regulating valve opens, which will eventually reduce the inlet pressure of the valve. Thus, the pressure is reduced. It can be seen from Figure 6(b) that when $A_{1}<A_{2}+A_{3}$, the greater the difference between $A_{2}+A_{3}$ and $A_{1}$, the higher the pressure at the inlet of the pressure-regulating valve, and the overflow valve loses its overflow effect. For example, when the regulation pressure of program $\mathrm{d}$ reaches 27.7 MPa, the regulation pressure of program e reaches $36.8 \mathrm{MPa}$. When the values of $A_{2}+A_{3}$ and $A_{1}$ are the same, the obtained simulation results are ideal.

(2) When the areas of $A_{2}+A_{3}$ and $A_{1}$ are the same, the different area parameters have little effect on the stable pressure of the valve inlet. Since the effect of the area is not obvious, the acting force on the pressure-regulating valve core is not much different, causing the inlet pressure to be the same. It can be seen from Figure 6(c) that as the value of area $A_{3}$ of the end of the tail vertebra increases, the overshoot of the inlet pressure decreases, and the response speed becomes faster. This is precisely because the pressure effect of the pressure-limiting valve chamber is more obvious. Moreover, this further shows that the multipressure stabilizing design of the combined relief 
TABLE 2: Pressure characteristics of the pressure-regulating and pressure-limiting combined relief valve and ordinary pilot relief valve.

\begin{tabular}{|c|c|c|c|c|}
\hline Name & $\begin{array}{c}\text { Pressure overshoot } \\
\text { rate }(\%)\end{array}$ & Regulated pressure $(\mathrm{MPa})$ & $\begin{array}{l}\text { Response } \\
\text { time }(\mathrm{ms})\end{array}$ & $\begin{array}{c}\text { Boost } \\
\text { time }(\mathrm{ms})\end{array}$ \\
\hline Pressure-regulating and pressure-limiting combined relief valve & 5.7 & 19 & 12 & 0.8 \\
\hline Ordinary pilot relief valve & 26 & 19 & 29 & 1.2 \\
\hline
\end{tabular}

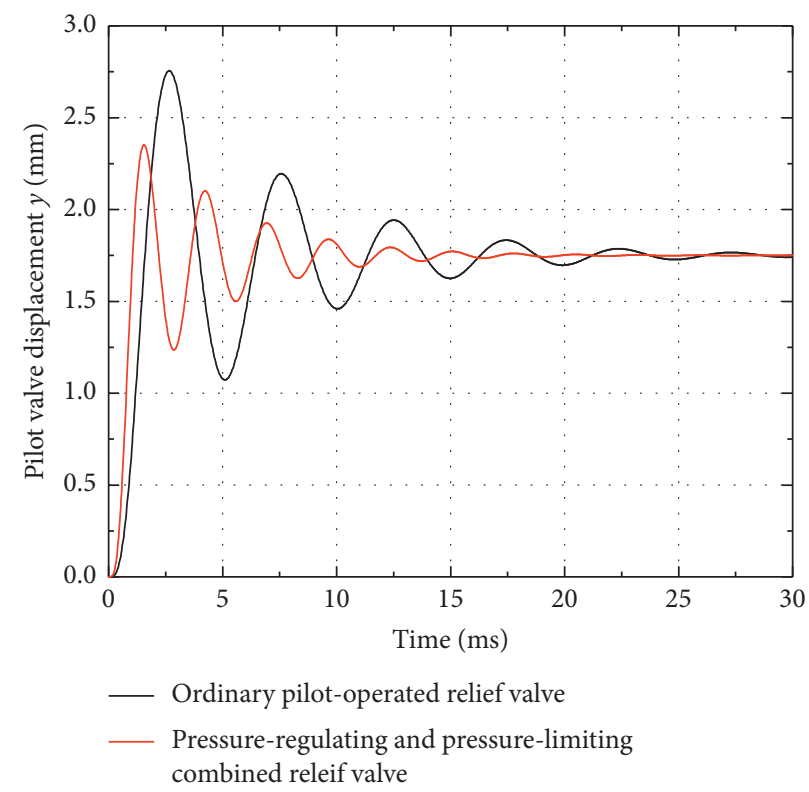

FIgURE 5: $x$ - $t$ curve under two kinds of relief valve flow steps.

TABLE 3: Test schemes under different area parameters.

\begin{tabular}{lcccccccc}
\hline Area relationship & \multicolumn{3}{c}{$A_{1} \geq A_{2}+A_{3}$} & \multicolumn{3}{c}{$A_{1} \leq A_{2}+A_{3}$} & \multicolumn{3}{c}{$A_{1}=A_{2}+A_{3}$} \\
Program & $\mathrm{a}$ & $\mathrm{b}$ & $\mathrm{f}$ & $\mathrm{c}$ & $\mathrm{d}$ & $\mathrm{f}$ & $\mathrm{e}$ & $\mathrm{f}$ \\
\hline$A_{1}\left(\mathrm{~cm}^{2}\right)$ & 1.5 & 1.5 & 1.5 & 1.5 & 1.5 & 1.5 & 1.4 & 1.5 \\
$A_{2}\left(\mathrm{~cm}^{2}\right)$ & 1.2 & 1.2 & 1.2 & 1.2 & 1.2 & 1.2 & 1.2 & 1.2 \\
$A_{3}\left(\mathrm{~cm}^{2}\right)$ & 0.1 & 0.2 & 0.3 & 0.4 & 0.5 & 0.3 & 0.2 & 0.3 \\
\hline
\end{tabular}

valve is conducive to the rapid stability of the pressure-regulating valve core. For example, compared with program $\mathrm{g}$, the overshoot of the inlet pressure of program $\mathrm{f}$ increases by $2.1 \%$, and the response time increases by $11 \%$. Compared with program e, the overshoot of the inlet pressure of program $\mathrm{f}$ decreases by $2.6 \%$, and the response time decreases by $18 \%$.

4.3. Influence of the Liquid Resistance Diameter of the Pressure-Limiting Valve. The combined relief valve is provided with three fixed liquid resistances, wherein the pressure $p_{3}$ in the valve cavity of the pressure-limiting valve is related to the liquid resistance $R_{3}$ of the valve core of the pressure-limiting valve. The diameters of the liquid resistance $R_{3}$ of the pressure-limiting valve were set to $0.6 \mathrm{~mm}$, $1.0 \mathrm{~mm}, 1.4 \mathrm{~mm}$, and $1.8 \mathrm{~mm}$. The pressure response curve of the sensitive cavity of the pressure-limiting valve is shown in Figure 7, and the inlet pressure response curve of the relief valve is shown in Figure 8. The following conclusions can then be drawn through analysis.

The different liquid resistance $R_{3}$ diameter has a significant effect on the dynamic characteristics of the valve and has almost no effect on the stable pressure of the pressure-limiting valve sensitive cavity and the inlet stable pressure. The stable pressure is $19 \mathrm{MPa}$, and in the process of approaching the steady state, the sensitive cavity pressure $p_{3}$ and the input pressure $p_{1}$ feature comparable fluctuations. If the diameter of the liquid resistance $R_{3}$ is too small, the damping effect of the sensitive cavity of the pressure-limiting valve is large, resulting in an instantaneous impact of the overflow valve and a large overshoot. If the diameter of the liquid resistance $R_{3}$ is too large, the effect of the sensitive cavity is reduced and becomes stable. Also, the time becomes longer, the overshoot of the shock moves backward, and the vibration gets more intense. When the diameter of the liquid resistance $R_{3}$ is $1-1.4 \mathrm{~mm}$, the inlet pressure response curve of the relief valve is ideal. 


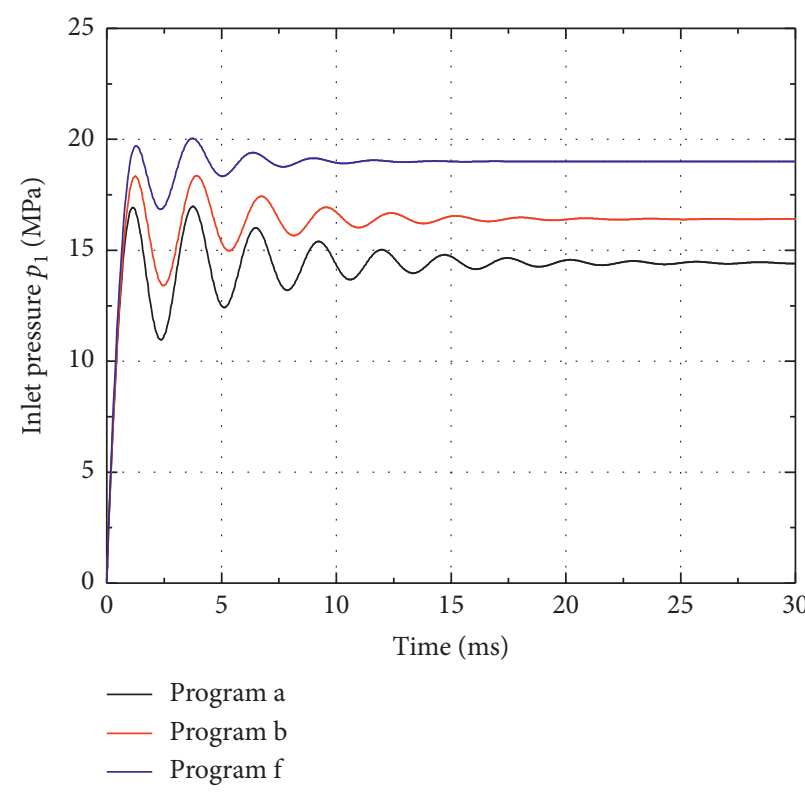

(a)

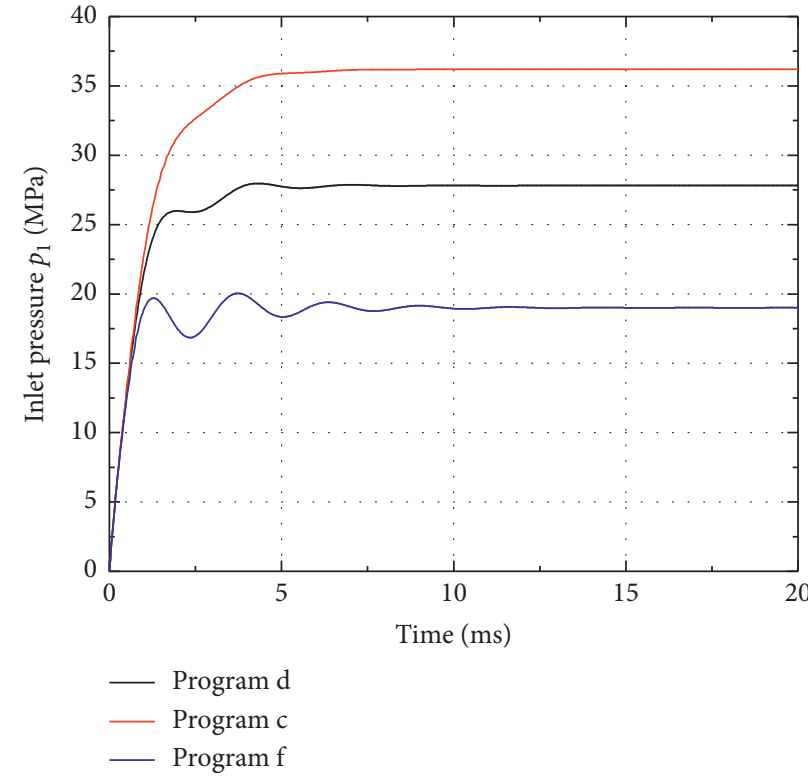

(b)

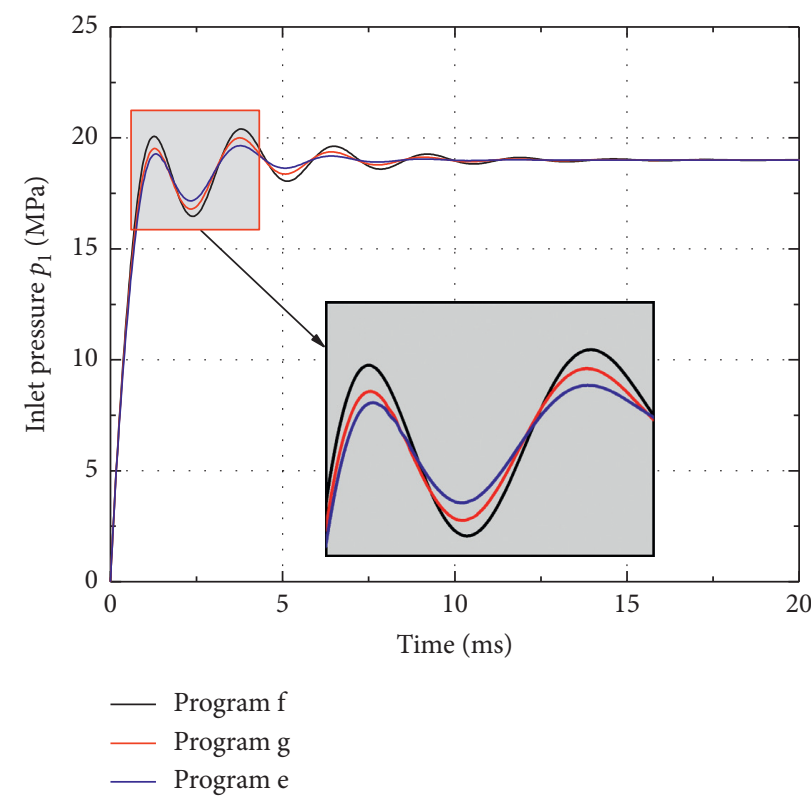

(c)

Figure 6: $p_{1}$ - $t$ curves under different end face diameters. (a) $A_{1} \geq A_{2}+A_{3}$. (b) $A_{1} \leq A_{2}+A_{3}$. (c) $A_{1}=A_{2}+A_{3}$.

It should be pointed out that the smaller the diameter of the damping hole, the greater the difficulty of processing, and the worse the anti-pollution ability in actual use, the greater the maintenance cost. This influencing factor should be considered in the design of the valve.

4.4. Influence of the Volume of the Relief Valve Sensitive Cavity. The pressure-regulating and pressure-limiting valves of the combined overflow valve are, respectively, provided with a sensitive cavity, which works together with the liquid resistance to generate hydraulic pressure at the three force- bearing ends of the pressure-regulating valve core. In the simulation, the volumes $\left(V_{2}, V_{3}\right)$ were set to $5 \mathrm{~cm}^{3}, 15 \mathrm{~cm}^{3}$, and $25 \mathrm{~cm}^{3}$, respectively. Figure 9 shows the simulation results of the main valve port pressure $p_{1}$ under different sensitive cavity volumes. The following conclusions can be drawn through analysis.

The value of the volume of different sensitive cavities has a significant effect on the dynamic characteristics of the combined relief valve and has almost no effect on the stable pressure of the valve inlet, which is $19 \mathrm{MPa}$. It can be seen from Figure 9 that the influence of the pressure-sensitive valve volume $V_{3}$ and the pressure-sensitive valve volume $V_{2}$ 


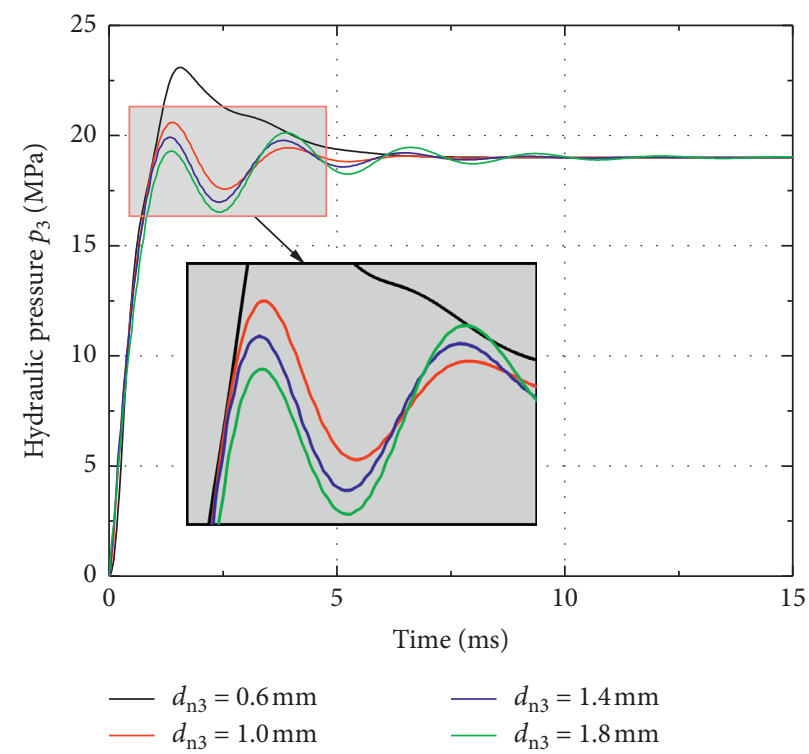

FIgURE 7: $p_{3}$ - $t$ curve under different pressure-limiting valve hydraulic resistance diameters.

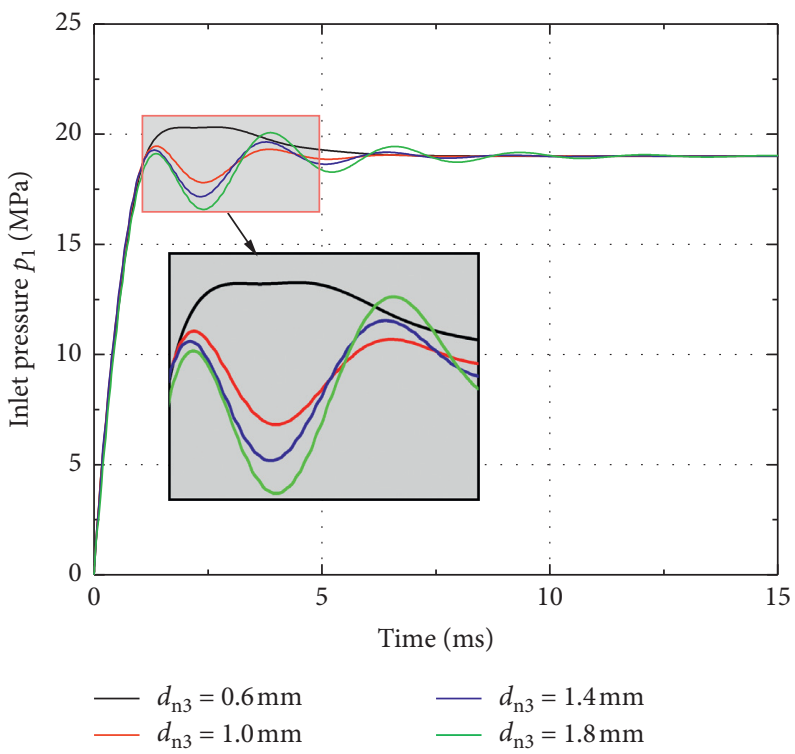

FIGURE 8: $p_{1}-t$ curve under different pressure-limiting valve hydraulic resistance diameters.

under different parameters on the dynamic performance is similar. When the volume of the sensitive cavity is too small, the pressure build-up speed is fast, and the peak time of the relief valve is short. However, the pressure overshoot is high, so the transition time is long, and there is a certain fluctuation in the inlet pressure, especially when the volume of the sensitive cavity is too large. The effect of the sensitive cavity is not obvious, the dynamic performance is not good, as it is prone to oscillation, and the response becomes slow. When the volume changes in a small range, the impact of the dynamic performance of the relief valve slightly changes. On the other hand, the multipressure stabilizing design of the combined relief valve can relieve the volume of the sensitive cavity to a certain extent and improve the stability of the relief valve. For example, when the volume of the sensitive cavity $V_{3}$ of the pressure-limiting valve is unchanged, compared with $V_{2}=15 \mathrm{~cm}^{2}$, the overshoot at $V_{2}=5 \mathrm{~cm}^{2}$ increases by $4 \%$, and the peak time increases by $33 \%$. Even though the degree of overshoot remained unchanged at $V_{2}=25 \mathrm{~cm}^{2}$, the time until reaching the peak increased by $300 \%$. When the volume $V_{2}$ of the sensitive cavity of the pressure-regulating valve is unchanged, the overshoot at $V_{3}=5 \mathrm{~cm}^{2}$ increases by $4 \%$ compared with $V_{3}=25 \mathrm{~cm}^{2}$, but the time to reach the peak is shortened by $70 \%$ in comparison with $V_{3}=15 \mathrm{~cm}^{2}$. Although the overshoot at $V_{3}=5 \mathrm{~cm}^{2}$ increased by $4 \%$, the time to reach the peak was shortened by $63 \%$. Further simulation results show that when $V_{2}$ takes a value of $5 \mathrm{~cm}^{2}$ and $V_{3}$ takes a value of about 


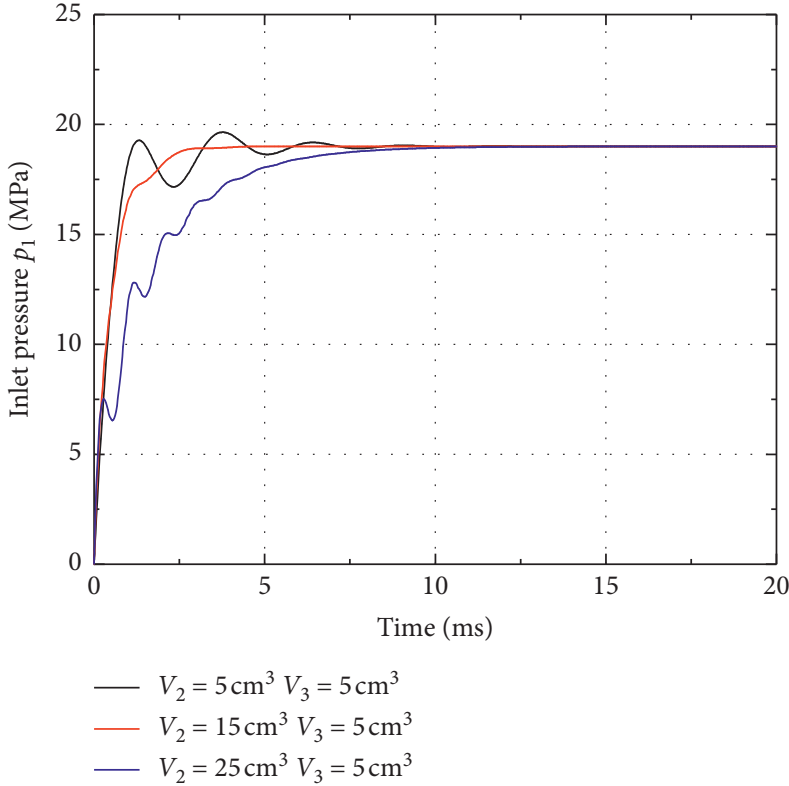

(a)

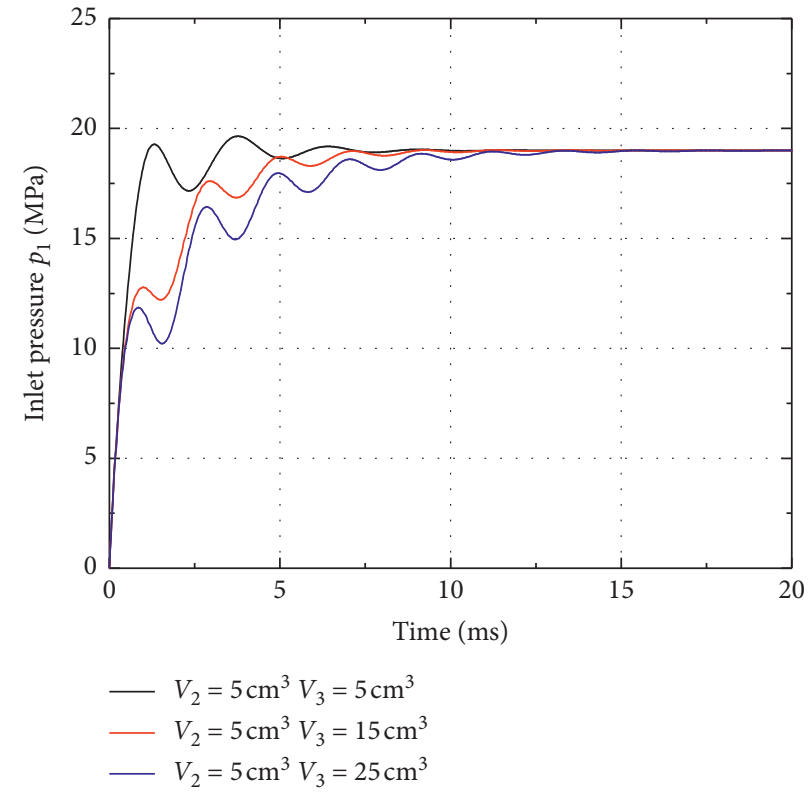

(b)

FIGURE 9: $p_{1}-t$ curves under different sensitive cavity volumes. (a) Simulation results of the sensitive cavity volume of different pressurelimiting valves. (b) Simulation results of the sensitive cavity volume of different pressure-regulating valves.

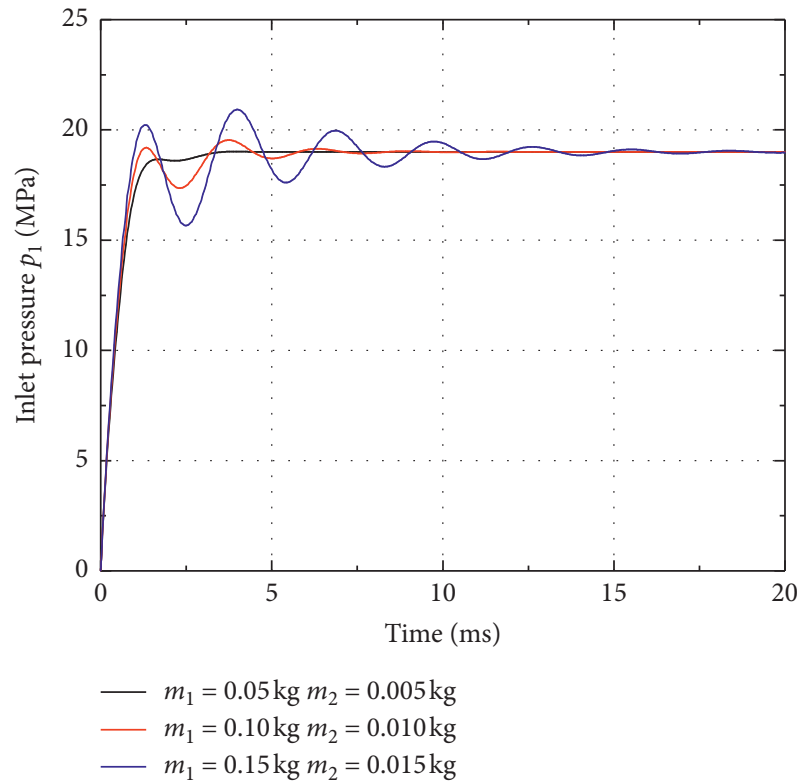

FIGURE 10: Simulation results of the different valve core quality values.

$15 \mathrm{~cm}^{2}$, the dynamic performance curve of the relief valve is ideal.

4.5. Influence of the Valve Core Mass. In the simulation, the valve core mass was set as follows. First, the pilot valve core mass $m_{2}=0.005 \mathrm{~kg}$, and the pressure-regulating valve core mass $m_{1}=0.05 \mathrm{~kg}$. Second, the pilot valve core mass $m_{2}=0.01 \mathrm{~kg}$, and the pressure-regulating valve core mass $m_{1}=0.1 \mathrm{~kg}$. Third, the pilot valve core mass $m_{2}=0.015 \mathrm{~kg}$, and the pressure-regulating valve core mass $m_{1}=0.15 \mathrm{~kg}$. Figure 10 shows the simulation results of the valve inlet pressure $p_{1}$ under different valve core quality values. This comparison makes it clear that with the increasing mass of the piston, the excess pressure of the input pressure of the valve increases, the oscillation phenomenon is significantly intensified, and the reaction time gets longer. Fully considering its dynamic properties of the piston, it is important to ensure that coil quality should be as low as possible within a reasonable range. Further simulations showed that when the mass changes within a small range, the impact of the dynamic performance of the relief valve slightly changes. When the mass value is too large, the simulation results diverge, that is, the combination valve loses its stability.

\section{Conclusion}

To construct a pressure-regulating and pressure-limiting cooperative working mechanism of double relief valves, reduce its vibration and noise, and improve its stability, a new idea of pressure-regulating and pressure-limiting cooperative work is proposed, and a new structure of pressure-regulating and pressure-limiting combined relief valve is designed. Combining the previous research methods on the dynamic characteristics of ordinary relief valves, this paper establishes a mathematical model of the combined relief valve under normal working conditions and uses Simulink software to simulate its pressure-regulating dynamic characteristics. The conclusions were then drawn as follows. 
(1) The mutual offset of the force on the end face of the piston reduces the fluctuation of the input pressure, which effectively increases the response speed and stability of the overflow valve, and hydraulic pressure acting on the rear vortex of the pressure control piston delivers the preload force for the overflow valve, partially replacing the spring stiffness effect of the pilot valve, which hardly changes the spring force and results in a reduction of the amplitude of oscillation in the main coil and the pilot coil, helping to provide a higher seal against the valve seat and thereby extending the life of the valve. When the parameters are similarly selected, the pressure overshoot of the combined pressure relief valve becomes $5.2 \%$, the response time becomes $12 \mathrm{~ms}$, and the boost time becomes $0.8 \mathrm{~ms}$, which is better than the $24 \%$ pressure overshoot of the ordinary pilot relief valve. Thus, the valve port pressure fluctuation is small, the work is stable, and the valve core vibration is effectively reduced.

(2) The matching relationship between the effective force area of the lower cavity of the pressureregulating valve core flange, the effective force area of the upper side of the pressure-regulating valve core flange, and the area at the end of the tail vertebrae has a great influence on the dynamic performance of the relief valve. When $A_{1}=A_{2}+A_{3}$, the simulation result of the relief valve is the most ideal one, and the set pressure is $19 \mathrm{MPa}$, which meets the design requirements. When $A_{1}<A_{2}+A_{3}$, the inlet pressure of the relief valve greatly fluctuates, and the dynamic performance becomes poor. When $A_{1}>A_{2}+A_{3}$, the stable pressure at the inlet of the relief valve significantly increases, and the relief valve loses its overflow effect.

(3) The liquid resistance diameter of the pressurelimiting valve and the volume of the sensitive cavity of the pressure-limiting valve influence the pressure $p_{3}$ of the sensitive cavity of the pressure relief valve directly and therefore have an indirect effect on the inlet pressure $p_{1}$. The simulation results show that an excessively large hydraulic resistance $R_{3}$, a diameter $d_{\mathrm{n} 3}$, and a pressure-limiting valve sensitive cavity volume $V_{3}$ make the pressure-limiting valve sensitive cavity function less, so the stability time becomes longer, the impact overshoot moves back, and the vibration becomes severe. The sensitive cavity volume $V_{3}$ and the sensitive cavity volume $V_{2}$ have similar effects on the dynamic performance, and in the process of approaching the steady state, the pressure-limiting valve sensitive cavity pressure $p_{3}$ and the valve inlet pressure $p_{1}$ have similar fluctuation rules. It was further explained that the multipressure stabilizing design of the combined relief valve is beneficial for the stability of the pressureregulating valve core.

(4) When the mass value of the valve core is too large, the inlet pressure overshoot of the valve is large, and the oscillation phenomenon is violent. When the mass value continues to expand, the simulation results diverge, and the combined overflow valve loses its stability. For the valve core, the quality should be as little as possible within a reasonable range.

\section{Data Availability}

The data used to support the findings of this study are included within the article.

\section{Conflicts of Interest}

The authors declare that they have no conflicts of interest.

\section{Acknowledgments}

The authors would like to thank Anhui University of Science and Technology for its support. This study was financially supported by the National Natural Science Foundation of China (no. 51675003), the Top-Notch Talent Program of University (Profession) in Anhui Province (gxbjZD11), and the Anhui Provincial Natural Science Foundation (no. 2008085QE216).

\section{References}

[1] K. Baghestan, S. M. Rezaei, H. A. Talebi, and M. Zareinejad, "An energy-saving nonlinear position control strategy for electro-hydraulic servo systems," ISA Transactions, vol. 59, pp. 268-279, 2015.

[2] C. Bazsó and C. J. Hős, “An experimental study on the stability of a direct spring loaded poppet relief valve," Journal of Fluids and Structures, vol. 42, pp. 456-465, 2013.

[3] K. Suzukia and E. Urataa, "Development of a direct pressure-sensing water hydraulic relief valve," International Journal of Fluid Power, vol. 9, no. 2, pp. 5-13, 2009.

[4] K. Suzukia and E. Urataa, "Dynamic characteristics of a direct pressure sensing water hydraulic relief valve," in Proceedings of the 6th JFPS International Symposium on Fluid Power, pp. 461-466, Tsukuba, Japan, November 2005.

[5] G. L. Si, F. Y. Yang, W. J. Wang, and Y. H. Liu, "Study on relief valve with permanent magnetic spring," Advanced Materials Research, vol. 328-330, pp. 224-227, 2011.

[6] F. Chen-Yao, Y. Li-Man, L. I. Yun-Hua, and S. I. Guo-Lei, "Design theory of relief valve with permanent magnet spring," Hydraulic and Pneumatic, vol. 10, pp. 34-38, 2017.

[7] K. Dang, L. Yang, Y. Li, S. I. Guolei, J. Chen et al., "Optimum design of direct relief valve with air gap combination of permanent magnet spring," Journal of Mechanical Engineering, vol. 54, no. 20, pp. 297-303, 2018.

[8] W. Jia, Y. Chenbo, H. Fei, L. I. Guo, and X. Fan, "Dynamic characteristics and stability analysis of conical relief valve," Mechanika, vol. 25, no. 1, pp. 25-31, 2019.

[9] Y. Yao-Bao, Y. Jia-Yang, and J.-Y. Fu, "Characteristics of two-stage relief valve with series damping orifice in the front chamber of pilot valve," Journal of Jilin University (Engineering and Technology Edition), vol. 47, no. 1, pp. 129-136, 2017.

[10] Y. Liu, X. Mao, D. Wu, and S. Yang, "Design and simulation of a seawater hydraulic relief valve," Huazhong University of Science and Technology (Natural Science Edition), vol. 38, no. 9, pp. 125-128, 2010. 
[11] R.-P. Li, S.-L. Nie, M.-L. Yi, and J. Ruan, "Simulation investigation on fluid characteristics of jet pipe water hydraulic servo valve based on CFD," Journal of Shanghai University (English Edition), vol. 15, no. 3, pp. 201-206, 2011.

[12] L. I. Hai-Ning, J. Zhang, C.-L. Cao, and Y.-Y. Pan, "Study and improvement analysis of dynamic characteristics of overflow valve," Coal Technology, vol. 37, no. 9, pp. 247-249, 2018.

[13] D. N. Johnston, K. A. Edge, and M. Brunelli, "Impedance and stability characteristics of a relief valve," Proceedings of the Institution of Mechanical Engineers, Part I: Journal of Systems and Control Engineering, vol. 216, no. 5, pp. 371-382, 2002.

[14] J. Liu, H. Xie, L. Hu, H. Yang, and X. Fu, "Flow force regulation of the main poppet in a large flow load control valve," Proceedings of the Institution of Mechanical Engineers, Part A: Journal of Power and Energy, vol. 231, no. 8, pp. 706-720, 2017.

[15] H. Chattopadhyay, A. Kundu, B. K. Saha, and T. Gangopadhyay, "Analysis of flow structure inside a spool type pressure regulating valve," Energy Conversion and Management, vol. 53, no. 1, pp. 196-204, 2012.

[16] L. Huan-Long, J. I. Xiao-Wei, K. E. Jian, and W. U. Wen-Hai, "Analysis on the pressure characteristics of direct relief valve using active control," Machinery Design \& Manufacture, vol. 1, pp. 5-7, 2018.

[17] L. Huan-Long, Y. Tang, B. Deng, W. Wen-Hai, and C. Kai, "Effects of damping structures on pressure characteristics of poppet valve," Science Technology and Engineering, vol. 15, no. 16, pp. 58-62, 2015.

[18] J. Zou, F. Lin, and C. Ji, "Capillary breakup of armored liquid filaments," Physics of Fluids, vol. 29, no. 6, 2017.

[19] C. Ji, B. Li, and F. Y. Lin, "Outcomes following single bubble collapse in a rigid tube," in Proceedings of the 9th International Symposium on Cavitation (CAV2015), vol. 656, no. 1, Lausanne, Switzerland, December 2015.

[20] J. Zou, B. Li, and C. Ji, "Interactions between two oscillating bubbles in a rigid tube," Experimental Thermal and Fluid Science, vol. 61, no. 11, pp. 105-112, 2015.

[21] M. T. Muller and R. C. Fales, "Design and analysis of a two-stage poppet valve for flow control," International Journal of Fluid Power, vol. 9, no. 1, pp. 17-26, 2008.

[22] R. D. Eyres, A. R. Champneys, and N. A. J. Lieven, "Modelling and dynamic response of a damper with relief valve," Nonlinear Dynamics, vol. 40, no. 2, pp. 119-147, 2005.

[23] S. J. Zheng, "CFD study for the flow filed inside the hydraulic poppet valve considering of the movement of cone," Dissertation, Taiyuan University of Technology, Taiyuan, China, 2005. 